\title{
Comparison of Antibacterial Activity of Trans-cinnamaldehyde, 1, 8 Cineole, and Pulegone Against Streptococcus equi subsp equi Isolated from Horse

\author{
Yaser Nozohour ${ }^{1 *}$, Ghader Jalilzadeh-amin ${ }^{1}$
}

1. Department of Internal Medicine and Clinical Pathology, Faculty of Veterinary Medicine, Urmia University, Urmia, Iran

\section{ABSTRACT}

Background and Aim: Strangle in the horses is the commonest and the most significant infectious disease. An antibiotic of the first choice, commonly Penicillin, is used for antimicrobial therapy. Due to side effects and resistance against used antibiotics, interest in novel antimicrobial substances from other sources, including herbal medicine as safe agents has been raised. This study evaluated the antibacterial susceptibility profile of Streptococcus equi subsp equi in the confrontation of Trans-cinnamaldehyde, 1, 8 Cineole, and Pulegone on bacterial pathogens isolated from the horse.

Materials and Methods: Two hundred clinically isolates were studied by the single disk method to Ampicillin, Ciprofloxacin, Trimethoprim sulfamethoxazole, Gentamicin, Enrofloxacin, Chloramphenicol, Azithromycin, Cefotaxime, Oxytetracycline, Erythromycin, and Penicillin. Paper discs were prepared by impregnation in $10 \mu \mathrm{L}$ essential oils main compounds (EOMC). The antibacterial activities of Trans-cinnamaldehyde, 1, 8 Cineole, and Pulegone were evaluated by microbroth dilution and disk diffusion methods against isolates of $S$. equi.

Results \& Conclusion: All the isolates were resistant to Trimethoprim-sulfamethoxazole and Cefotaxime. The maximum growth inhibition zone was related to Oxytetracycline and Ampicillin. The growth inhibition zone diameter was $30 \mathrm{~mm}, 20$ $\mathrm{mm}$, and $26 \mathrm{~mm}$ for Trans-cinnamaldehyde, Pulegone, and 1, 8 Cineole, respectively. The results of the Minimum inhibitory concentrations (MICs) and Minimum Bactericidal Concentrations (MBCs) showed that Trans-cinnamaldehyde had the highest antibacterial activity compared to other EOMC against S. equi. This study indicated that Trans-cinnamaldehyde, 1 , 8 Cineole, and Pulegone revealed antibacterial properties; therefore, these main constituents of the medicinal plant could be a safe candidate for the new antibacterial products.

Keywords: Antibacterial Activity; Cinnamic aldehyde; Eucalyptol; Pulegone; Streptococcus equi

Received: 2021/06/30; Accepted: 2021/08/11; Published Online: 2021/09/20

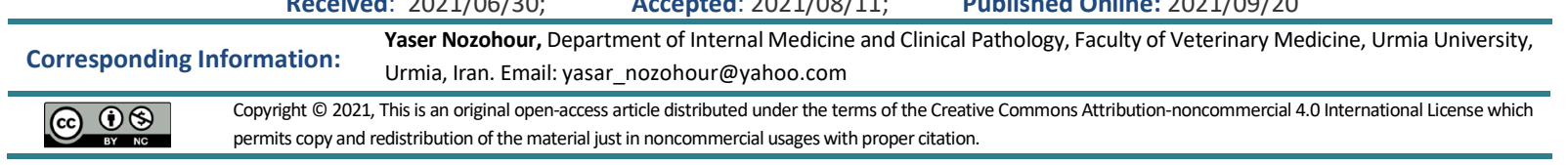

Use your device to scan and read the article online

Nozohour Y, Jalilzadeh-amin G. Comparison of antibacterial activity of Trans-cinnamaldehyde, 1, 8 Cineole, and Pulegone against Streptococcus equi subsp equi Isolated from Horse. Iran J Med Microbiol. 2021; 15 (5) :606-611

\section{Download citation: BibTeX | RIS | EndNote | Medlars | ProCite | Reference Manager | RefWorks}

Send citation to: $8 \underline{\text { Mendeley }} \overline{\text { Zotero }} \underline{\mathbb{H}_{\text {RefWorks }}}$

\section{Introduction}

Streptococci that are pathogenic for equids include Streptococcus equi, Streptococcus zooepidemicus, and Streptococcus dysgalactiae, which cause strangles, respiratory disease, metritis, and infrequent etiologies of lymphadenitis and placentitis $(1,2)$. S. equi subsp. equi, is a Gram-positive bacterium that produces a beta-hemolysin, characterized by hemolysis around colonies growing on blood agar. S. equi causes strangle, a highly contagious infection in the upper respiratory tract and associated lymph nodes $(\mathbf{1}, 2)$. Given that this disease is one of the most important diseases in horses, choosing the appropriate drug for treatment is extremely important $(1,2)$. The clinical form of the disease manifests as an acute disease of varying severity, with the presence of guttural pouches and retropharyngeal lymph node infection, and as a chronic 
disease is associated with metastatic infection in other organs of the upper respiratory tract (2). In the treatment of bacterial-induced respiratory disease in the horse, Penicillin, enrofloxacin, chloramphenicol, and gentamicin are commonly used (2). Antibiotics bear several side effects, including kidney failures such as toxic nephritis and liver failures, as well as neurologic signs observed in horses (3). Given the development of antimicrobial resistance (AMR), the use of various safe sources such as essential oil, extract, and other agents from plants has been proposed as alternative agents to be substituted with synthetic antibiotics (4). It has been shown that medicinal plants and their compounds could effectively hinder the growth of microorganisms (5-7). Trans-cinnamaldehyde (TC) is an aromatic aldehyde that is extracted as the main component of the bark extract of cinnamon, Cinnamomum zeylandicum. This compound possesses antimicrobial activity against numerous microorganisms (7-9). 1, 8Cineole (Eucalyptol) is a biologically active terpene, as a chief constituent present in essential oils of several popular aromatic plants and spice oils like Mentha longifolia, Thymus vulgaris, Zingiber officinale, Rosmarinus officinalis, and Artemisia dracunculus $(10,11)$. Pulegone is a natural monoterpene ketone obtained from the essential oil of a variety of plants (12, 13). Pulegone bears antibacterial, pesticidal, antifeedent, and insect repellant properties (14). S. equi is an important pathogenic bacterium in horses, which has recently been the subject of antibiotic resistance, and new alternative drugs with fewer side effects should be sought, and herbs can be considered as a good alternative in this regard. Considering that Transcinnamaldehyde, 1, 8 Cineole, and Pulegone are present in a wide range of medicinal plants, comparing these three substances' effects can help determine the antibacterial effect of medicinal plants against $S$. equi. Therefore, this study evaluated the antibacterial susceptibility profile of $S$. equi in the confrontation of Trans-cinnamaldehyde, 1, 8 Cineole, and Pulegone on bacterial pathogens isolated from the horses.

\section{Materials and Methods}

\section{Chemicals}

Trans-cinnamaldehyde, 1, 8 Cineole, and Pulegone as essential oils main compounds (EOMC) and Reassuring powder were purchased from Sigma (Chemical Co., St. Louis, MO).

\section{Isolation and Identification of Bacteria}

In this study, nasal swab samples were collected from 200 horses with the history of a respiratory disease. The sterile nasal swab sample was prepared and transferred to a sterile tube. The samples were transferred to the laboratory as soon as possible under ice and cultured on a blood agar medium and were incubated at $37^{\circ} \mathrm{C}$ for
24-48 h. The colonies suspected to Streptococcus spp. were carefully chosen, and after Gram staining, their morphology was observed under a microscope. Catalase and oxidase tests were accomplished on purified samples. Streptococcus diagnostic media were used to culture Gram-positive cocci, catalase-negative and negative oxidizing bacteria. The basic biochemical characteristics using standard bacteriological techniques were adopted to identify the isolates (15).

\section{Antibacterial Activity Assay}

Using micro broth dilution and agar disk diffusion, antibacterial properties of the essential oils were assessed (16). First of all, Muller-Hinton agar (Merck ${ }^{\circledR}$, Germany) was used to culture bacterial suspensions from clinical isolates prepared in sterile normal saline. To perform a disk diffusion test, sterile filter paper discs (6 $\mathrm{mm}$ in diameter) were impregnated in $10 \mu \mathrm{L}$ EOMC (Trans-cinnamaldehyde 99\%, 1, 8 Cineole 99\%, and Pulegone $96 \%$ ) separately and left to dry completely for 20-25 minutes, then placed on the inoculated culture medium. In this study, to determine the antibiotic susceptibility of $S$. equi isolates against 11 different antibiotic classes, the Kirby-Bauer disk diffusion susceptibility test was performed according to the Clinical and Laboratory Standards Institute recommendations (CLSI). The antibiotic disks included Trimethoprim Sulfamethoxazol (SXT, 25 $\mu \mathrm{g}$ ), Enrofloxacin (NFX, $5 \mu \mathrm{g}$ ) Chloramphenicol (C, $30 \mu \mathrm{g}$ ),

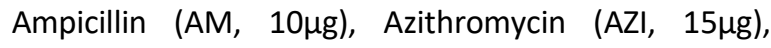

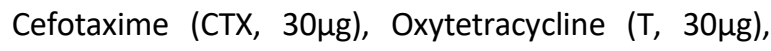

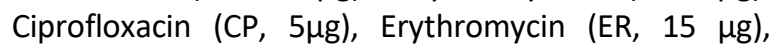

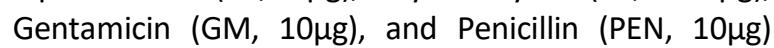
(Padtan Teb Co, Iran).

\section{Determination of Minimum Inhibitory Concentration and Minimum Bactericidal Concentration}

The broth microdilution method was conducted to determine the Minimum Inhibitory Concentration (MIC) and Minimum Bactericidal Concentration (MBC) of the EOMC. MIC and MBC were tested in the microplate reader, using 96 well plates. Each well of microplate was loaded with a total volume of $100 \mu \mathrm{L}$ containing Mueller-Hinton broth (MHB). Different concentrations of each EOMC were prepared by serial dilution in $\operatorname{MHB}(17,18)$. One hundred microliters of inoculums contain $5 \times 10^{5} \mathrm{CFU} / \mathrm{mL}$ of test bacteria were added to each well. Positive control and negative controls were noticed. Reassuring powder was diluted in distilled water $(1 \mathrm{mg} / \mathrm{mL}$ and $10 \mu \mathrm{L})$ was added to each well. Incubation was done at $37^{\circ} \mathrm{C}$ for $24 \mathrm{~h}$. The MIC was determined by the lowest concentration of EOMC which would inhibit the growth of bacteria apparently. $20 \mu \mathrm{L}$ of the suspension of well before were cultured on $\mathrm{BHI}$ agar for evaluation of $\mathrm{MBC}$ (17).

\section{Statistical Analysis}

All tests were repeated in triplicate. The mean and standard deviation (SD) of the growth inhibition zone 
diameter in the disk-diffusion method as well as the MIC and MBC of the EOMC, Gentamicin, Cotrimoxazole, Tetracycline, Ciprofloxacin, Saftrixone, and Amoxicillin were determined. Data were analyzed using SPSS 19 (SPSS Inc., Chicago, III., USA).

\section{Results \& Discussion}

The results of the susceptibility test showed that $100 \%$ of isolates were resistant to Trimethoprimsulfamethoxazole (SXT), Cefotaxime (CTX30), 80\% to
Penicillin (P10), and 70\% to Azithromycin (AZI15). The diameter of the growth inhibition zones is $30 \mathrm{~mm}, 20$ $\mathrm{mm}$, and $26 \mathrm{~mm}$ for Trans-cinnamaldehyde, Pulegone, and 1, 8 Cineole, respectively. Oxytetracycline and Ampicillin created the largest diameter of the growth inhibition zone (Figure 1, 2, and Tables 1). The results of the MICs and MBCs tests showed that Transcinnamaldehyde (MIC: $33.57 \pm 12.69 \mathrm{mg} \mathrm{mL}^{-1}$ and $\mathrm{MBC}$ : $67.15 \pm 25.38 \mathrm{mg} \mathrm{mL}^{-1}$ ) has the highest and Pulegone (MIC: $307.00 \pm 76.75 \mathrm{mg} \mathrm{mL}^{-1}$ and MBC: $460.5 \pm 00.00$ $\mathrm{mg} \mathrm{mL}^{-1}$ ) has the lowest effect of antibacterial had against $S$. equi. Details are presented in Table 2.

Table 1. Percentage of Isolates Susceptible, Moderately Susceptible or Resistant to Each Antibiotic Disk Diffusion Method

\begin{tabular}{|c|c|c|c|}
\hline Antibiotic & Resistant (\%) & Intermediate (\%) & Sensitive (\%) \\
\hline Amoxicillin (AMX25) & - & - & 100 \\
\hline Penicillin (P10) & 80 & 10 & 10 \\
\hline Gentamicin (GM10) & - & - & 100 \\
\hline Enrofloxacin (NFX5) & - & - & 100 \\
\hline Cefotaxime (СТХ30) & 100 & - & - \\
\hline Trimethoprim (SXT) & 100 & - & - \\
\hline Chloramphenicol (C30) & - & - & 100 \\
\hline Azithromycin (AZI15) & 70 & - & 30 \\
\hline Ciprofloxacin (CP5) & - & - & 100 \\
\hline Erythromycin(E15) & - & - & 100 \\
\hline Oxytetracyclin (T-30) & - & - & 100 \\
\hline
\end{tabular}

Table 2. MICs and MBCs of Trans-cinnamaldehyde, 1, 8 Cineole, and Pulegone against clinically isolated bacteria

\begin{tabular}{|c|c|c|c|c|c|c|}
\hline \multirow[b]{2}{*}{ Bacteria } & \multicolumn{2}{|c|}{ Trans-cinnamaldehyde } & \multicolumn{2}{|c|}{ 1, 8 Cineole } & \multicolumn{2}{|c|}{ Pulegone } \\
\hline & $\begin{array}{c}\mathrm{MIC} \\
\left(\mathrm{mg} \mathrm{mL}^{-1}\right)\end{array}$ & $\begin{array}{c}\mathrm{MBC} \\
\left(\mathrm{mg} \mathrm{mL}^{-1}\right)\end{array}$ & $\begin{array}{c}\mathrm{MIC} \\
\left(\mathrm{mg} \mathrm{mL}^{-1}\right)\end{array}$ & $\begin{array}{c}\mathrm{MBC} \\
\left(\mathrm{mg} \mathrm{mL}^{-1}\right)\end{array}$ & $\begin{array}{c}\mathrm{MIC} \\
\left(\mathrm{mg} \mathrm{mL}^{-1}\right)\end{array}$ & $\begin{array}{c}\mathrm{MBC} \\
\left(\mathrm{mg} \mathrm{mL}^{-1}\right)\end{array}$ \\
\hline S. equi & $33.57 \pm 12.69$ & $67.15 \pm 25.38$ & $76.74 \pm 19.18$ & $153.5 \pm 38.37$ & $307.00 \pm 76.75$ & $460.5 \pm 00.00$ \\
\hline
\end{tabular}

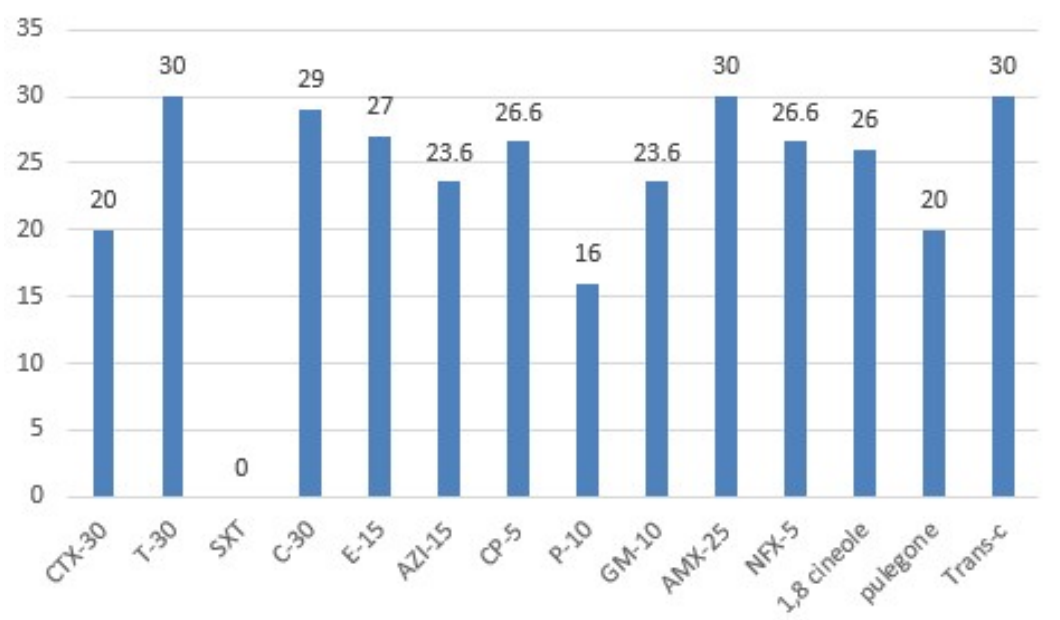

Figure 1. Diameter of inhibition zone $(\mathrm{mm})$ of Trans-cinnamaldehyde, 1, 8 Cineole, and Pulegone and antibiotic disk extracts tested against clinically isolated bacteria 
In the present study, one of the most important, contagious, and common pathogens of the equine respiratory system was evaluated. Strangle is considered one of the three most important and hazardous diseases of the equine respiratory system. The findings of the antibiogram test indicated that $S$. equi isolated from clinically ill animals were resistant to some common antibiotics like Trimethoprimsulfamethoxazole, Cefotaxime, Penicillin, and Azithromycin. Because of the extensive use of antimicrobials in veterinary practices, it appears that it is a chief cause of acquired bacterial resistance and could play a role in developing resistance to Trimethoprim-sulfamethoxazole, Cefotaxime, Penicillin, and Azithromycin. Regarding AMR observed in horses undergoing treatment with the common antibiotic combination, as shown in our study, the use of medicinal plants and their compounds has been proposed as a substitution for synthetic agents (antibiotic). Many studies worldwide have revealed that essential oils and other extracts of medicinal plants could hinder the growth of bacteria and fungi. Interestingly, it was discovered that nanoemulsion of Trans-cinnamaldehyde and 1,8 cineole had substantial antibacterial activity against $S$. aureus and E. coli (19). Others revealed that Transcinnamaldehyde had bacteriostatic and bactericidal activity against the Staphylococcus spp. (20).

The antimicrobial effects of Trans-cinnamaldehyde on airborne pathogens have been declared. Transcinnamaldehyde has antibacterial properties across an array of Gram-negative and Gram-positive bacteria, including Porphyromonas gingivalis, Staphylococcus spp., Listeria spp., Streptococcus pyogenes, Salmonella spp., Escherichia coli, Lactobacillus sakei, Vibrio spp., Cronobacter sakazakii, and Pseudomonas spp (21). A study of the therapeutic effect of 1,8-Cineole on pathogenic bacteria species present in chronic rhinosinusitis, showed an inhibiting effect of 1, 8-Cineole on these organisms (22). Another study showed that 1,8 Cineole has increased the antimicrobial activity of chlorhexidine gluconate against all microorganisms (methicillin-resistant $S$. aureus, S. aureus, E. coli, Candida albicans, $K$. pneumoniae, and Enterococcus faecalis) except $P$. aeruginosa (23). Another investigation showed that the essential oil of Mentha pulegium L. had a potent antimicrobial activity (24). It has been shown that the essential oil of lavender possessed more potent in vitro activity than the common antibiotics for the management of infections caused by $S$. equi subspecies (25). One study has shown that the essential oils from Mentha spicata and Mentha pulegium have antimicrobial activity, and these plants had high concentrations of Carvone and Pulegone can be used for treating microbe-related illnesses (26). The result of another study showed $M$. pulegium has good potential for control of Klebsiella infections (27). Multiple hypotheses have been suggested to explain the mechanism of action of essential oils antimicrobial activity, given that essential oils contain differences in structure. It should be considered that their antimicrobial activity may be associated with more than one specific mechanism, and this has reduced the resistance of bacteria to medicinal plants. Given that essential oils are hydrophobic, this critical property helps them target the lipid-containing bacterial mitochondria and cell membrane, and these compounds can impair membrane proteins, ending up the depletion of the proton motive force, leakage of cell contents, and coagulate cytoplasm. The proposed mechanisms could be activated as a consequence of another, resulting in a multiplicity of mechanisms or may act independently (28).

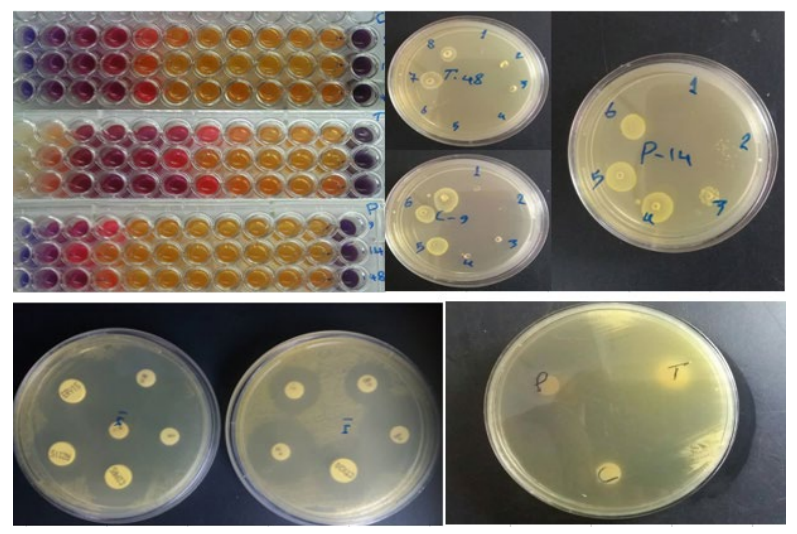

Figure 2. Microplates and plate showing the MICs, MBC, and diameter of inhibition zone $(\mathrm{mm})$ of Trans-cinnamaldehyde, 1, 8 Cineole, and Pulegone

The exact mechanisms of Trans-cinnamaldehyde, 1 , 8 Cineole, and Pulegone activity in $S$. equi infection needs further illumination. It was proposed that transcinnamaldehyde revealed an antimicrobial effect by binding the carbonyl group of proteins of bacteria and preventing the decarboxylation of amino acids (29). The findings of the minimum inhibitory and bactericidal concentration in this study showed that Trans-cinnamaldehyde, 1, 8 Cineole, and Pulegone had an effective antibacterial effect against $S$. equi.

\section{Conclusion}

The results of our study indicated that Transcinnamaldehyde, 1, 8 Cineole, and Pulegone had antibacterial properties and could be considered an available and affordable source and option for synthetic antibiotics in the treatment process of strangles. 


\section{Acknowledgment}

The authors would like to express their sincere appreciation and gratitude to all the technical staff of the Veterinary Hospital of Urmia University.

\section{References}

1. Duffee LR, Stefanovski D, Boston RC, Boyle AG. Predictor variables for and complications associated with Streptococcus equi subsp equi infection in horses. J Am Vet Med Assoc. 2015 Nov 15; 247(10):1161-8.

[DOI:10.2460/javma.247.10.1161] [PMID]

2. Constable PD, Hinchclif $\mathrm{KW}$, Done $\mathrm{SH}$, et al. Veterinary Medicine: A Textbook of the Diseases of Cattle, Horses, Sheep, Pigs and Goats .11th ed. 2017; 176-908.

3. Ghamarian A. compendium of data sheets for veterinary products. 2005-2006.

4. Zitterl-Eglseer K, Marschik T. Antiviral Medicinal Plants of Veterinary Importance: A Literature Review. Planta Med. 2020 Aug 10; 86(15):10581072. [DOI:10.1055/a-1224-6115] [PMID]

5. Danish P, Ali Q, Hafeez MM, Malik A. Antifungal and antibacterial activity of aloe vera plant extract. Biol Clin Sci Res J. 2020 Dec 12; e004. [DOI:10.54112/bcsri.v2020i1.4]

6. Syafiq R, Sapuan SM, Zuhri MY, Ilyas RA, Nazrin A, Sherwani SF, Khalina A. Antimicrobial activities of starch-based biopolymers and biocomposites incorporated with plant essential oils: A review. Polymers. $2020 \quad$ Oct; 12(10):2403. [DOI:10.3390/polym12102403] [PMID] [PMCID]

7. Hameed $\mathrm{IH}$, Altameme HJ, Mohammed GJ. Evaluation of antifungal and antibacterial activity and analysis of bioactive phytochemical compounds of Cinnamomum zeylanicum (Cinnamon bark) using gas chromatography-mass spectrometry. Oriental Journal of Chemistry. 2016; 32(4):1769. [DOI:10.13005/ojc/320406]

8. Munoz M, Torres-Pagan N, Peiro R, Guijarro R, Sanchez-Moreiras AM, Verdeguer $M$. Phytotoxic effects of three natural compounds: Pelargonic acid, carvacrol, and cinnamic aldehyde, against problematic weeds in Mediterranean crops. Agronomy. 2020 Jun; 10(6):791. [DOI:10.3390/agronomy10060791]

9. Du GF, Yin XF, Yang DH, He QY, Sun X. Proteomic Investigation of the Antibacterial Mechanism of trans-Cinnamaldehyde against Escherichia coli. J

\section{Conflict of interest}

The authors declared no competing financial interest.

Proteome Res. 2021; 20(5):2319-28. [DOI:10.1021/acs.jproteome.0c00847] [PMID]

10. Vuuren SV, Viljoen AM. Antimicrobial activity of limonene enantiomers and 1, 8-cineole alone and in combination. Flavour Fragr J. 2007; 22(6):540-4. [DOI:10.1002/ffj.1843]

11. Santos FA, Rao VS. 1, 8-cineol, a food flavoring agent, prevents ethanol-induced gastric injury in rats. Dig Dis Sci. 2001; 46(2):331-7. [DOI:10.1023/A:1005604932760] [PMID]

12. Farley $\mathrm{DR}$, Valerie $\mathrm{H}$. The natural variation of the pulegone content in various oils of peppermint. J. Sci. Food. Agric. 2006; 31: 1143-1151. [DOI:10.1002/jsfa.2740311104]

13. Jalilzadeh-Amin G, Maham M, Dalir-Naghadeh B, Kheiri F. Effects of Mentha longifolia essential oil on ruminal and abomasal longitudinal smooth muscle in sheep. J. Essent. Oil Res. 2012; 24: 61-69. [DOI:10.1080/10412905.2012.646019]

14. Dhingra AK, Chopra B, Bhardwaj S, Dhar KL. Synthesis and characterization of novel pulegone derivatives as substitutes of 4-(1, 1 dimethylethyl) cyclohexan-1-ol acetate. J. Pharm. Res. 2011; 4: 1921.

15. Cowan ST, Steel KJ. Cowan and Steel's Manual for the Identification of Medical Bacteria, third ed. Cambridge University Press, Cambridge. 1993.

16. Jorgensen J, Turnidge J. Susceptibility test methods: dilution and disk diffusion methods. In: Jorgensen J, Pfaller M, Carroll K, editors. Manual of Clinical Microbiology. 11th ed. Washington, DC: American Society of Microbiology. 2015; 12531273. [DOI:10.1128/9781555817381.ch71]

17. Nozohour, Y., Golmohammadi, R., Mirnejad, R., Fartashvand, M. Antibacterial Activity of Pomegranate (Punica granatum L.) Seed and Peel Alcoholic Extracts on Staphylococcus aureus and Pseudomonas aeruginosa Isolated From Health Centers. Journal of Applied Biotechnology Reports, 2018; 5(1): 32-36. [DOI:10.29252/JABR.01.01.06]

18. Nozohour Y, Golmohammadi R, Mirnejad R, Moghaddam MM, Fartashvand M. Comparison of Antibacterial Activities of Walnut (Juglans regia L.) 
and Pine (Pinus halepensis Mill.) Leaves Alcoholic Extracts against Bacteria Isolated from Burn Wound Infections. Acta Microbiologica Hellenica. 2019; 64(2):99-108.

19. Moghimi R, Aliahmadi A, Rafati H. Ultrasonic nanoemulsification of food grade transcinnamaldehyde: 1, 8-Cineol and investigation of the mechanism of antibacterial activity. Ultrason Sonochem. 2017; $35: 415-21$ [DOI:10.1016/j.ultsonch.2016.10.020] [PMID]

20. Shen S, Zhang T, Yuan Y, Lin S, Xu J, Ye H. Effects of cinnamaldehyde on Escherichia coli and Staphylococcus aureus membrane. Food Control. 2015; 47:196-202. [DOI:10.1016/i.foodcont.2014.07.003]

21. Doyle AA, Stephens JC. A review of cinnamaldehyde and its derivatives as antibacterial agents. Fitoterapia. 2019; 139:104405. [DOI:10.1016/i.fitote.2019.104405] [PMID]

22. Schürmann $M$, Oppel $F$, Gottschalk $M$, Büker $B$, Jantos CA, Knabbe C, Hütten A, Kaltschmidt B, Kaltschmidt $C$, Sudhoff $H$. The therapeutic effect of 1, 8-Cineol on pathogenic bacteria species present in chronic rhinosinusitis. Front Microbiol. 2019; 10:2325. [DOI:10.3389/fmicb.2019.02325] [PMID] [PMCID]

23. Şimşek M, Duman R. Investigation of effect of 1 , 8cineole on antimicrobial activity of chlorhexidine gluconate. Pharmacognosy research. 2017 Jul; 9(3):234. [DOI:10.4103/0974-8490.210329] [PMID] [PMCID]
24. Mahboubi M, Haghi G. Antimicrobial activity and chemical composition of Mentha pulegium L. essential oil. J Ethnopharmacol. 2008; 119(2):3257. [DOI:10.1016/j.jep.2008.07.023] [PMID]

25. Yaghoobpour M, Fozouni L, Ghaemi, P. A new solution for control of respiratory infection by Streptococcus equi isolated from horses in northern Iran. Bulg. J. Vet. Med. 2021.

26. Boukhebti H, Chaker AN, Belhadj H, Sahli F, Ramdhani M, Laouer $H$, Harzallah D. Chemical composition and antibacterial activity of Mentha pulegium L. and Mentha spicata L. essential oils. Der Pharmacia Lettre. 2011; 3(4):267-75.

27. Jazani NH, Ghasemnejad-Berenji H, Sadegpoor S. Antibacterial effects of Iranian Mentha pulegium essential oil on isolates of Klebsiella sp. Pakistan Journal of Biological Sciences. 2009 Jan 15; 12(2):183. [DOI:10.3923/pjbs.2009.183.185] [PMID]

28. Chouhan S, Sharma K, Guleria S. Antimicrobial activity of some essential oils-present status and future perspectives. Medicines. 2017; 4(3):58. [DOI:10.3390/medicines4030058] [PMID] [PMCID]

29. Ojagh SM, Rezaei M, Razavi SH, Hosseini, SMH. Investigations of antibacterial activity cinnamon bark essential oil (Cinnamomumzeylanicum) in vitro antibacterial activity against five food spoilage bacteria. J Food Tech. 2012; 9(35): 67-76. 